\title{
Metadherin regulates proliferation and metastasis via actin cytoskeletal remodelling in non-small cell lung cancer
}

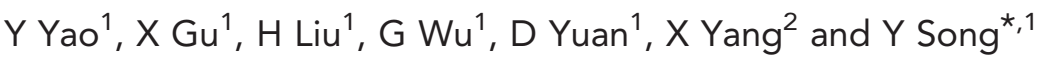 \\ ${ }^{1}$ Jinling Hospital, Department of Respiratory Medicine, Nanjing University, School of Medicine, Nanjing 210002, China and \\ ${ }^{2}$ Division of Medical Oncology, University of Colorado Anschutz Medical Campus, Aurora, CO 80045, USA
}

Background: Metaderin (MTDH) protein is a novel component part of tight junction complex. The aim of this study was to investigate the correlation between MTDH and prognosis of patients and to explore the role of MTDH on NSCLC development and metastasis.

Methods: Relative mRNA expression was evaluated by quantitative real-time PCR, and protein expression was detected using immunohistochemistry staining. The role of MTDH in cancer cell proliferation, migration and invasion was studied by modulation of MTDH expression in NSCLC cell lines. These functions of MTDH were further confirmed in vivo.

Results: In NSCLC, low MTDH protein expression was correlated with lymph node metastasis, TNM stage and decreased OS $(P=0.001,0.011$ and 0.013 , respectively). Overexpression of MTDH reduced anchorage-independent and -dependent growth through arresting cell cycle, inhibited migration and invasion in vitro and further suppressed tumorigenesis, tumour growth and metastasis in vivo. Knockdown of MTDH expression increased cell invasiveness. MTDH overexpression reversed pro-metastatic actin cytoskeleton remodelling and inhibited EMT, supporting that MTDH has a key role on cancer proliferation and metastasis.

Conclusions: MTDH has an important role in NSCLC proliferation and metastasis and provides potential in predicting metastasis and prognosis for patients with NSCLC.

Metastasis is responsible for the major mortality in lung cancer, which is the leading cause of cancer-associated death in the world (Siegel et al, 2013). Approximately two-thirds of non-small cell lung cancer (NSCLC) patients are diagnosed at an advanced stage, and $30 \%-50 \%$ of the remaining patients who can undergo surgery will develop recurrence with metastatic disease (Gibbons et al, 2009; Yao et al, 2013). If mechanism in the initiation of metastasis could be uncovered, it may provide an important therapeutic target for prevention or inhibition of metastasis in clinic.

It has been proposed that, in the processes of cancer metastasis, tumour cells execute the following steps: invasion in situ, intravasation, survival in circulation, extravasation, micrometastasis and final colonisation (Thompson et al, 2005; Chaffer and Weinberg, 2011). To date, it is well known that epithelial-mesenchymal transition (EMT) is a primary step to induce tumour cell invasion and metastasis in situ (Yang and Weinberg, 2008; Thiery et al, 2009; Gonzalez de Castro et al, 2013). In initiation of EMT, cell-cell adhesion, a key factor in maintaining epithelial morphology, is disrupted, followed by the cytoskeleton of epithelial cells transforming into mesenchyal-like cells (Acloque et al, 2009; Chao et al, 2009). These findings suggest that a protein that can enhance cell adhesion and inhibit cytoskeletal remodelling may provide an important target to suppress EMT and tumour metastasis.

In cell adhesion, tight junction is a specific junctional complex (Braga, 2002). The protein-protein interaction in tight junction proteins can link to the actin cytoskeleton, serving as a maintainer of cell structure (Yilmaz and Christofori, 2009). Loss of tight junction is proved to be an important step leading to the loss of 
cell-cell adhesion and final metastasis (Sawada et al, 2003; Martin and Jiang, 2009). Tight junction molecules, such as claudins, zona occludens $1(\mathrm{ZO}-1)$ and occludins, have been demonstrated in previous studies to be correlated with tumour progression and metastasis (Hoover et al, 1998; Gu et al, 2008; Chao et al, 2009). The expression of metaderin $(\mathrm{MTDH})$ protein, a component part of tight junction complex and marker of mature tight junction, has been demonstrated to be altered in various human cancers, including breast cancer (Brown and Ruoslahti, 2004; Hu et al, 2009a), hepatocellular carcinoma (Zhu et al, 2011) and head and neck squamous cell carcinoma (Nohata et al, 2011). However, the correlation of MTDH and NSCLC has still remained unexplored.

We hypothesised that MTDH protein controls the adhesion and cytoskeletal remodelling of cancer cells and thereby has a key role in the development and metastasis of NSCLC. The aim of this study was to investigate the correlation between MTDH expression and prognosis of NSCLC patients and to explore the effect and mechanism of MTDH on the development and metastasis of NSCLC.

\section{MATERIALS AND METHODS}

Patients and tissue sample collection. The research proposal related with patients was approved by chairman of the ethics committee at Jinling Hospital. Specimens from lung tumours and the corresponding adjacent normal tissues for mRNA level analysis were obtained from 38 patients with histologically confirmed NSCLC who underwent surgical resection at Jinling Hospital between 1 April 2011 and 30 July 2012. Protein level was assessed on tumour specimens from an independent cohort of 40 patients histologically diagnosed as
NSCLC and underwent surgical resection at the Jinling Hospital between 7 July 2000 and 23 October 2006.

Plasmid constructs and establishment Of MTDH-overexpressing cell line. Full length of MTDH coding sequence was cloned into PCR 3.1-HA(c) (presented by Professor Huang of Nanjing University Animal Model Research Center). Constructs were confirmed by restriction and sequence analysis. SiRNA that specifically targeted MTDH sequence were designed or purchased (Genepharma, Shanghai, China) (The sequence of primer sequence for full length of MTDH coding sequence is shown in Supplementary Table S1 and Supplementary Table S2 shows sequences of siRNAs).

Stable MTDH-overexpressing NSCLC cells were established by integrating MTDH gene into the genomic DNA of human NSCLC cell lines using Lipofectamine 2000 Reagent (Invitrogen, Shanghai, China).

Quantitative real-time PCR (Q-PCR), immunohistochemistry (IHC) staining, immunofluorescence (IF) staining and western blotting. We used Q-PCR for quantitative analysis of mRNA level and IHC staining for evaluation of protein expression in cancer tissues. IF staining was used to identify MTDH expression site and cell structure, and western blotting was used for evaluating protein level of EMT markers in cells (Primer sequences for real-time PCR are shown in Supplementary Table S3).

Cell culture. Human lung cancer cell lines A549, H1299 and H1650 (from ATCC, Manassas, VA, USA) were cultured. Anchoragedependent and -independent growth ability of cells was assessed by MTT, Edu proliferation assay and soft agar assay, respectively. Proliferation capacity was further confirmed by cell cycle assay. We then used scratch wound and transwell assays to evaluate the migration and invasion ability of cells.
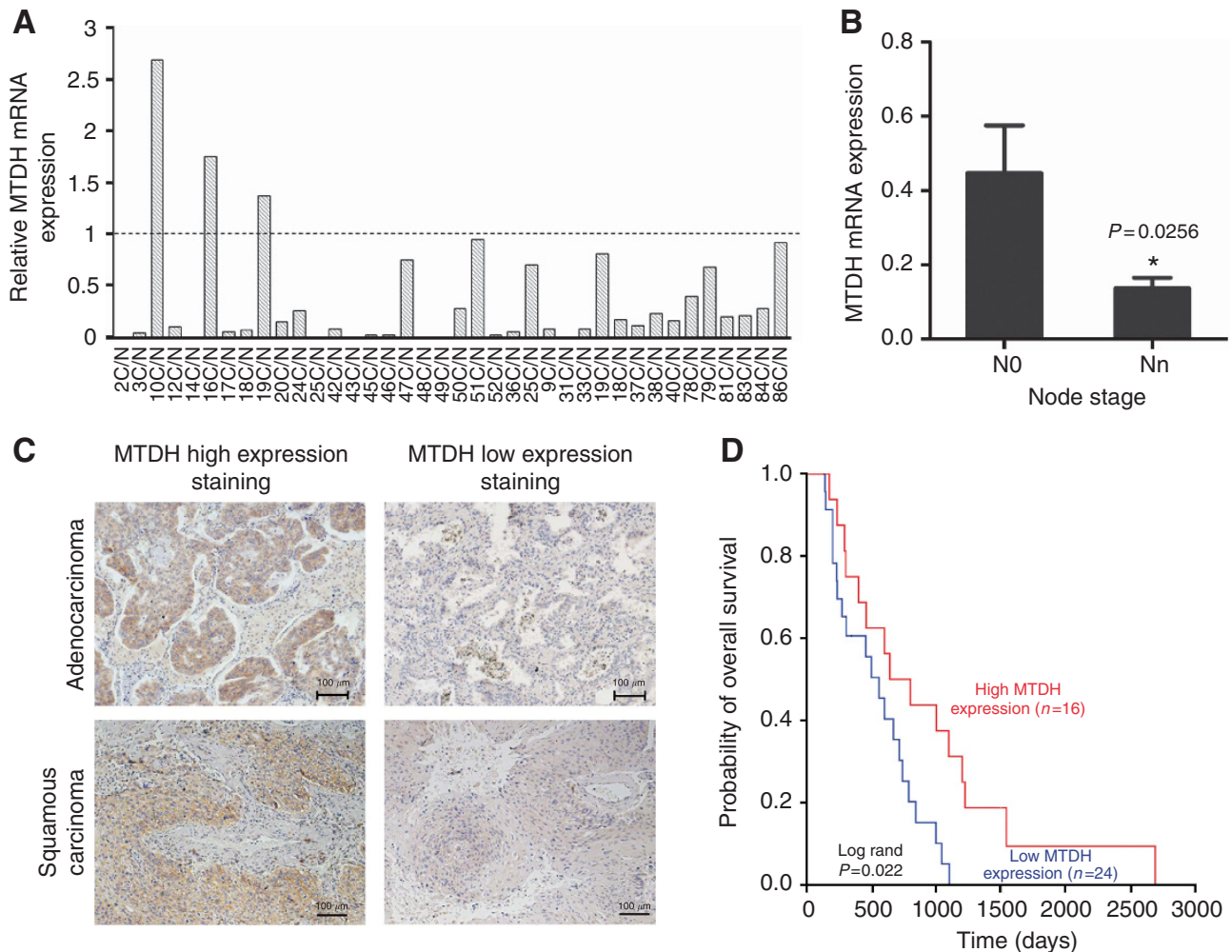

Figure 1. Metadherin (MTDH) expression levels are associated with prognosis of patients with NSCLC. (A) Q-PCR analysis of MTDH mRNA levels in 38 pairs of primary tumours and corresponding normal lung tissues. (B) MTDH mRNA levels in patients with or without lymph node metastasis ( $n=26$ and 12). Data are mean \pm s.d. ${ }^{*} P=0.0256$. (C) Immunohistochemical staining of high expression and low expression of MTDH in tumour specimens from lung cancer patients with adenocarcinoma and squamous carcinoma, respectively. (D) Kaplan-Meier estimates of overall survival in 40 patients with surgically resected NSCLC. The median MTDH staining score was served as a cutoff to divide patients into high and low MTDH expression groups. Red line: patients with high MTDH expression, blue line: patients with low MTDH expression. Low MTDH protein expression was associated with significantly decreased overall survival $(P=0.013$, log-rank test). 
Animal work. All mouse studies were approved by the animal centre at Jinling Hospital. For proliferation experiment, $2 \times 10^{6}$ cells were injected subcutaneously in the right flank of 6-week-old $\mathrm{BALB} / \mathrm{c}$ nude mice ( $n=12$ per group). Mice were killed at 8 weeks, and primary tumours were isolated. For metastasis experiment, $1 \times 10^{6}$ cells were injected into the lateral tail veins of 6 -week-old $\mathrm{BALB} / \mathrm{c}$ nude mice ( $n=5$ per group), killed at 12 weeks, and primary tumours and sites of metastasis were isolated.

Statistical analyses. Chi-squared test was performed to compare baseline clinical characteristics between patients in different groups. Survival curve was estimated by Kaplan-Meier analysis and the log-rank test was utilised to examine the significance of the differences in survival distributions between groups.

Data are presented as mean \pm s.d. The difference between the two groups was analysed using the unpaired Student's $t$-test, and Kruskal-Wallis analysis was used to test the differences between multiple groups. These statistical analyses were performed using the SPSS18 (SPSS, Chicago, IL, USA) and Prism statistical program (GraphPad, La Jolla, CA, USA). All statistical tests were two-sided, and $P$-value $<0.05$ was considered statistically significant.

\section{RESULTS}

MTDH expression predicts metastasis and prognosis for NSCLC patients. In the total 38 pairs of NSCLC tissues and corresponding normal lung tissues (clinical characteristics shown

\begin{tabular}{|c|c|c|c|}
\hline MTDH expression & Low & High & $P$-value \\
\hline No. of patients & 24 & 16 & \\
\hline Age (years, mean \pm s.d.) & $59.3 \pm 12.8$ & $57.9 \pm 9.3$ & \\
\hline $\begin{array}{l}\leqslant 65 \\
>65\end{array}$ & $\begin{array}{l}15 \\
10\end{array}$ & $\begin{array}{r}11 \\
4\end{array}$ & 0.392 \\
\hline \multicolumn{4}{|l|}{ Gender } \\
\hline $\begin{array}{l}\text { Female } \\
\text { Male }\end{array}$ & $\begin{array}{l}12 \\
13\end{array}$ & $\begin{array}{r}2 \\
13\end{array}$ & 0.026 \\
\hline \multicolumn{4}{|l|}{ Smoking status } \\
\hline $\begin{array}{l}\text { Never } \\
\text { Ever }\end{array}$ & $\begin{array}{r}16 \\
9\end{array}$ & $\begin{array}{l}6 \\
9\end{array}$ & 0.140 \\
\hline \multicolumn{4}{|l|}{ Histology } \\
\hline $\begin{array}{l}\text { Non-squamous } \\
\text { Squamous }\end{array}$ & $\begin{array}{l}14 \\
11\end{array}$ & $\begin{array}{l}8 \\
7\end{array}$ & 0.870 \\
\hline \multicolumn{4}{|l|}{ Lymph metastasis } \\
\hline $\begin{array}{l}\text { None } \\
\text { Ever }\end{array}$ & $\begin{array}{r}6 \\
19\end{array}$ & $\begin{array}{r}12 \\
3\end{array}$ & 0.001 \\
\hline \multicolumn{4}{|l|}{ TNM stage } \\
\hline $\begin{array}{l}\text { I } \\
\text { II } \\
\text { III } \\
\text { IV }\end{array}$ & $\begin{array}{r}4 \\
12 \\
8 \\
1\end{array}$ & $\begin{array}{r}10 \\
4 \\
1 \\
0\end{array}$ & 0.011 \\
\hline \multicolumn{4}{|l|}{ Overall survival } \\
\hline Days (median) & 500 & 800 & 0.013 \\
\hline
\end{tabular}

in Supplementary Table S4), relative mRNA expression of MTDH in 35 NSCLC tissues was reduced compared with the normal tissue (Figure 1A). After normalisation by the basal expression of corresponding normal lung tissues, the mean mRNA expression of MTDH was $0.363 \pm 0.091$ in all pairs. MTDH mRNA level in 26 patients with N0 stage was significantly higher than that in 12 patients with lymph node metastasis $(P=0.0256)$, as shown in Figure 1B.

The result of IHC revealed that, compared with benign tumour, the protein expression of MTDH was also decreased in NSCLC tissues. Interestingly, we found that lung cancer tissues with no lymph node metastasis show higher MTDH expression (Supplementary Figure S1). According to the intensity and range of positive staining, 40 NSCLC patients (Supplementary Table S5) were divided into two groups, with 24 patients in the low MTDH expression group and 16 in the high MTDH expression group. As shown in Table 1, MTDH expression had a significant correlation with lymph node metastasis and TNM stage $(P=0.001$ and 0.011 , respectively). The median overall survival (OS) time in all 40 patients was 600 days, and median OS time in the low and high MTDH expression group was 500 days and 800 days, respectively. Low MTDH protein expression was significantly associated with decreased OS (Figure 1D $P=0.013$ ).

Results of univariate analysis demonstrated that MTDH was a prognostic predictor. OS prognostic variables were MTDH $(\mathrm{HR}=2.601, P=0.017)$ and gender $(\mathrm{HR}=0.487, P=0.043)$

Table 2. Result of univariate analysis with respect to OS in 40 NSCLC patients

\begin{tabular}{|c|c|c|c|}
\hline \multirow[b]{2}{*}{ Variables } & \multicolumn{3}{|c|}{ Overall survival } \\
\hline & HR & $95 \% \mathrm{Cl}$ & $P$-value \\
\hline \multicolumn{4}{|l|}{ MTDH } \\
\hline $\begin{array}{l}\text { High }(n=16) \\
\text { Low }(n=24)\end{array}$ & $\begin{array}{c}1 \\
2.601\end{array}$ & $1.190-5.685$ & 0.017 \\
\hline \multicolumn{4}{|l|}{ Age (years) } \\
\hline $\begin{array}{l}\leqslant 65(n=26) \\
>65(n=14)\end{array}$ & $\begin{array}{c}1 \\
0.996\end{array}$ & $0.489-2.029$ & 0.991 \\
\hline \multicolumn{4}{|l|}{ Gender } \\
\hline $\begin{array}{l}\text { Female }(n=14) \\
\text { Male }(n=26)\end{array}$ & $\begin{array}{c}1 \\
0.487\end{array}$ & $0.243-0.978$ & 0.043 \\
\hline \multicolumn{4}{|l|}{ Smoking status } \\
\hline $\begin{array}{l}\text { Non-smoker }(n=22) \\
\text { Smoker }(n=18)\end{array}$ & $\begin{array}{c}1 \\
0.670\end{array}$ & $0.339-1.323$ & 0.249 \\
\hline \multicolumn{4}{|l|}{ Histology } \\
\hline $\begin{array}{l}\text { Non-squamous }(n=22) \\
\text { Squamous }(n=18)\end{array}$ & $\begin{array}{c}1 \\
0.534\end{array}$ & $0.251-1.135$ & 0.103 \\
\hline \multicolumn{4}{|l|}{ Lymph metastasis } \\
\hline $\begin{array}{l}\text { None }(n=18) \\
\text { Ever }(n=22)\end{array}$ & $\begin{array}{c}1 \\
1.611\end{array}$ & $0.790-3.288$ & 0.190 \\
\hline \multicolumn{4}{|l|}{ TNM stage } \\
\hline $\begin{array}{l}\text { I }(n=14) \\
\text { II }(n=16) \\
\text { III }(n=9) \\
\text { IV }(n=1)\end{array}$ & $\begin{array}{c}1 \\
0.822 \\
1.138 \\
6.896\end{array}$ & $\begin{array}{c}0.373-1.808 \\
0.454-2.854 \\
0.765-62.192\end{array}$ & $\begin{array}{l}0.626 \\
0.783 \\
0.085\end{array}$ \\
\hline
\end{tabular}



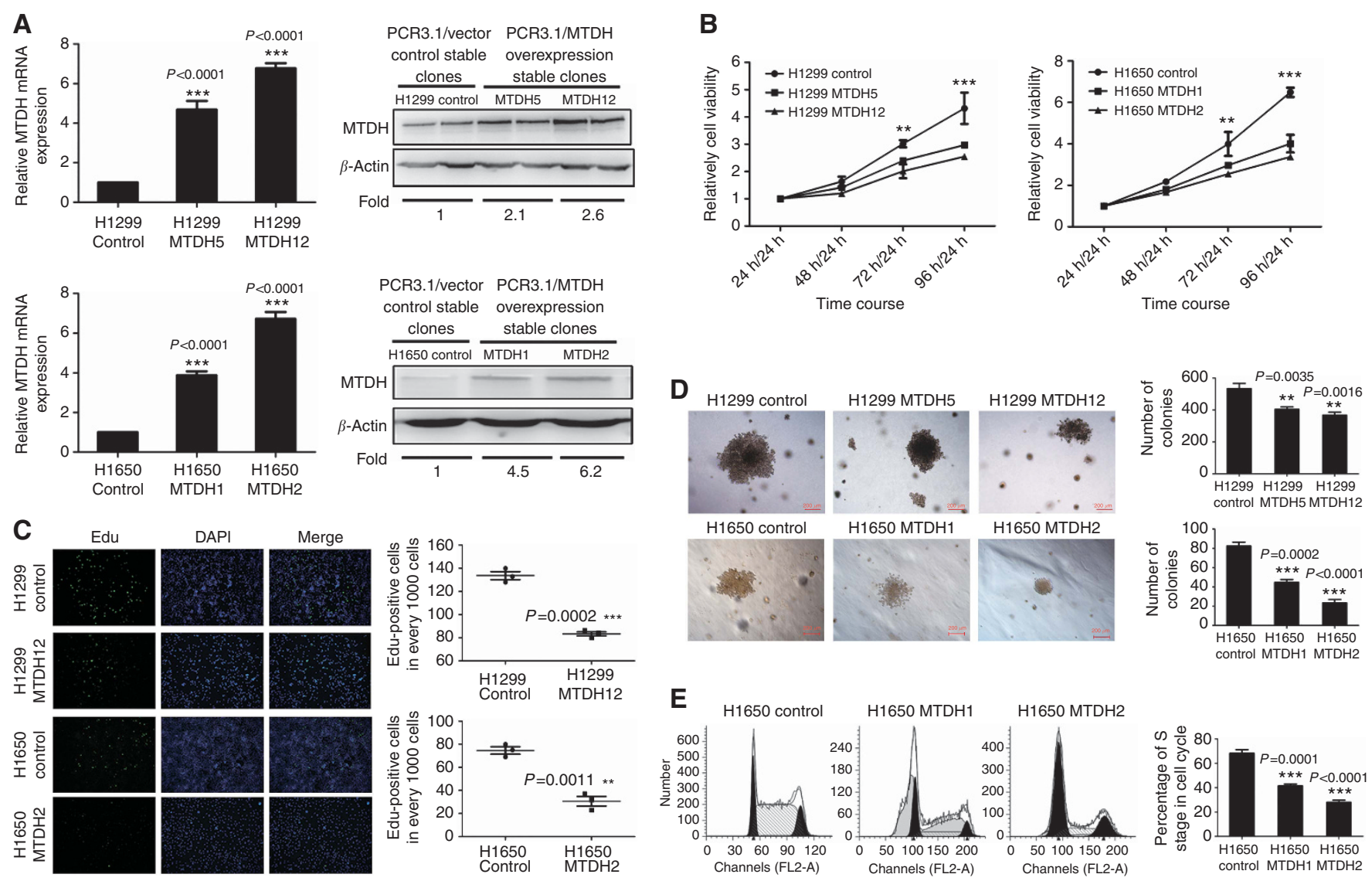

Figure 2. MTDH expression inhibits NSCLC cell proliferation in vitro. (A) Q-PCR and western blotting analyses for expression of MTDH in H1299 and $\mathrm{H} 1650$ control clones, selected stably transfected high MTDH-expressing clones (H1299 MTDH12 and H1650 MTDH2) and lowMTDHexpressing clones (H1299 MTDH5 and H1650 MTDH1). GAPDH and $\beta$-actin were, respectively, used as control for mRNA and protein. Fold of MTDH expression was normalised to the expression of control cells. ${ }^{\star \star \star} P<0.0001$ compared with vector control cells. (B) MTT assay of H1299/H1650 control and MTDH-overexpressing H1299/H1650 cells. Cell absorbance at $24 \mathrm{~h}$ was used as reference. Cell proliferation in MTDH-overexpressing cells was significantly decreased at $72 \mathrm{~h} / 24 \mathrm{~h}$ and $96 \mathrm{~h} / 24 \mathrm{~h}$. ${ }^{\star \star} P<0.01,{ }^{\star \star \star} P<0.001$ compared with vector control cells. (C) EdU cell proliferation assay of H1299/H1650 control and MTDH-overexpressing H1299/H1650 cells. ${ }^{\star \star \star} P=0.0002$ compared with vector control cells. The numbers of EdU-binding cells in MTDH-overexpressing H1299/H1650 cells were significantly reduced. ${ }^{\star \star} P=0.0011$ compared with vector control cells. (D) Anchorage-independent growth ability. Colony size was smaller in MTDH-overexpressing H1299/H1650 cells, and the number of colonies in MTDH-overexpressing $\mathrm{H} 1299 / \mathrm{H} 1650$ cells was significantly reduced. ${ }^{\star \star} P<0.01,{ }^{\star \star \star} P<0.001$ compared with vector control cells. (E) Cell cycle analysis of $\mathrm{H} 1650$ vector control and MTDH-overexpressing cells. The percentage of S phase in cell cycle was significantly decreased in MTDHoverexpressing cells. Data are mean \pm s.d. ${ }^{\star} P<0.05$ compared with vector control cells.

Figure 3. Cell migration and invasion were suppressed and actin cytoskeletal remodelling was regulated by MTDH expression in vitro. (A) Scratch wound-healing assays. Migratory ranges in MTDH-overexpressing H1299 cells (H1299 MTDH5 and MTDH12) were significantly less than that in parental H1299 control cells. (B) Migratory and invasive abilities of H1299 control and MTDH-overexpressing H1299 (H1299 MTDH5 and MTDH12) and H1650 control and MTDH-overexpressing H1650 cells (H1650 MTDH1 and MTDH2) by transwell assay. Upper panel: After $12 \mathrm{~h}$, cells migrated through the chamber. Lower panel: After $24 \mathrm{~h}$, cells invaded through the chamber with matrigel. (C) The number of migratory and invasive cells in $\mathrm{H} 1299$ control and MTDH-overexpressing H1299 and H1650 control and MTDH-overexpressing H1650 cells. The number of migratory and invasive cells through the chamber was significantly decreased in H1299 M5 and M12 cells compared with control cells and in H1650 M1 and M2 cells compared with control cells. Each experiment was repeated at least three times. Data are mean \pm s.d. ${ }^{*} P<0.01$, $\star \star \star P<0.001$ compared with control. (D) Morphological appearance of H1299/H1650 control and MTDH-overexpressing H1299/H1650 (H1299 MTDH5 and MTDH12, H1650 MTDH1 and MTDH2) cells. The vector control cells exhibited an elongated, spindle-shaped and mesenchymal-like morphology, while MTDH-overexpressing cells exhibited an epithelial-like polygon appearance, smoother cell edge and increased cell adhesion. (E) Cellular cyto-immunofluorescence. MTDH dominantly existed in cytoplasm. In MTDH-overexpressing cells, F-actin-enriched filopodial extensions were decreased. (F) Enlarged figures of cell structures. Arrowheads: F-actin filaments aggregation and filopodia. F-actin filament aggregation and filopodia in cells' leading edge was significantly decreased in MTDH-overexpressing H1299/H1650 cells. (G) Early cell migration

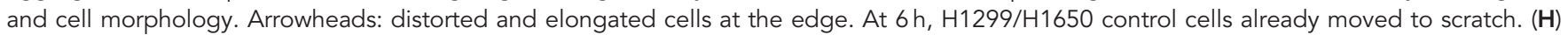
F-actin structure of cells at early migration. Upper panel: Actin cytoskeleton of H1299 cells at $6 \mathrm{~h}$ after scratch. Pro-metastatic cytoskeleton with actin-rich filopodia was shown in the leading edge of $\mathrm{H} 1299$ control cells. Lower panel: Actin cytoskeleton of H1650 cells at $6 \mathrm{~h}$ after scratch. Compared with MTDH-overexpressing cells, actin cytoskeleton was remodelled to pro-metastatic, spindle-shaped and mesenchymal-like structure in the leading $\mathrm{H} 1650$ control cell. (I) The area of migratory cell at the leading edge. The cell size was significantly increased in MTDHoverexpressing cells. Each experiment was repeated at least three times. Data are mean \pm s.d. ${ }^{\star} P<0.05,{ }^{*} P<0.01$ compared with control. 
(Table 2). After adjusting these two prognostic factors in the multivariate logistic regression analysis, the result revealed that MTDH was an independent prognostic factor for OS in NSCLC patients $(P=0.038)$.
According to the histology of the NSCLC tissues, the difference of MTDH expression between adenocarcinoma and squamous cell carcinoma was also analysed. As shown in Supplementary Figure S2 and Table 1, both mRNA expression and protein

A
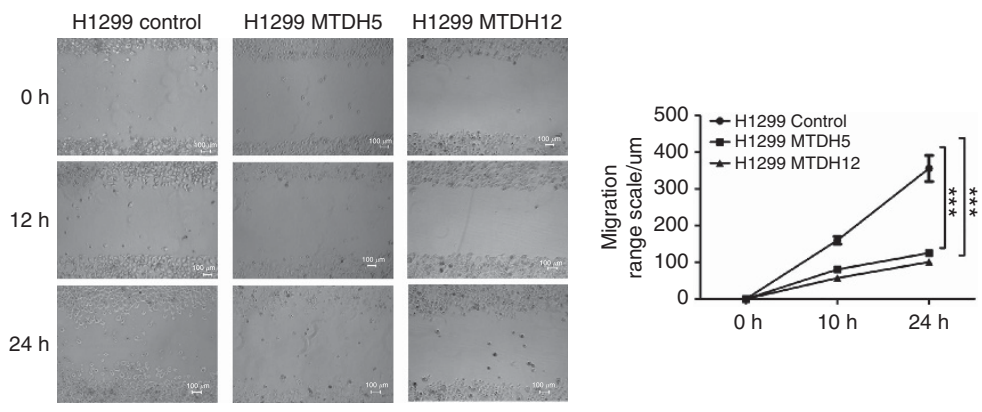

B
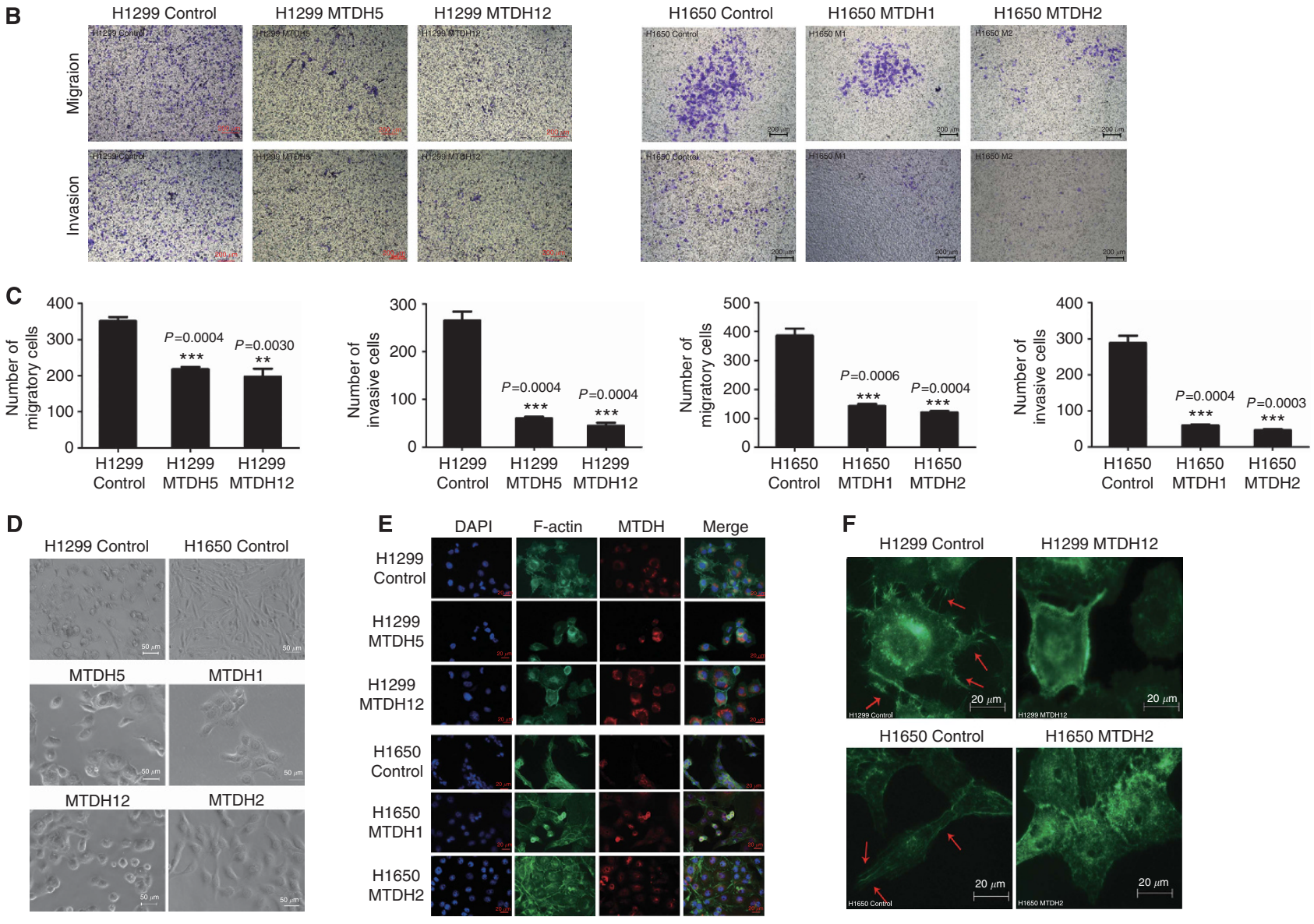

G

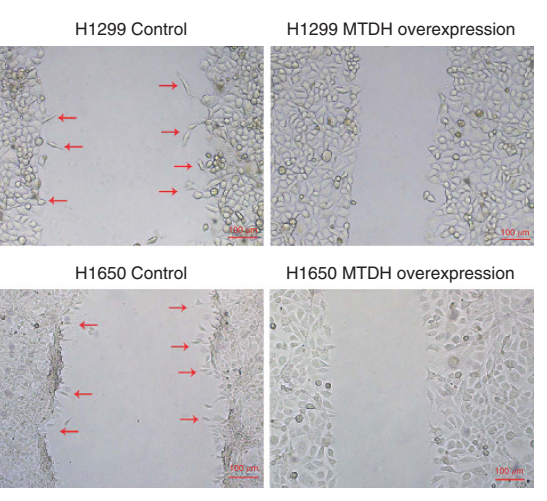

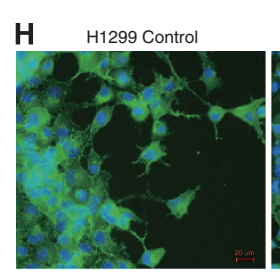

H1650 Control

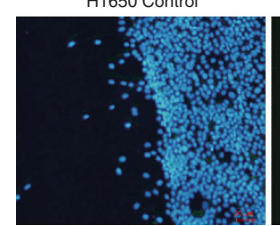

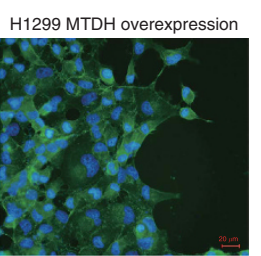

H1650 MTDH overexpression
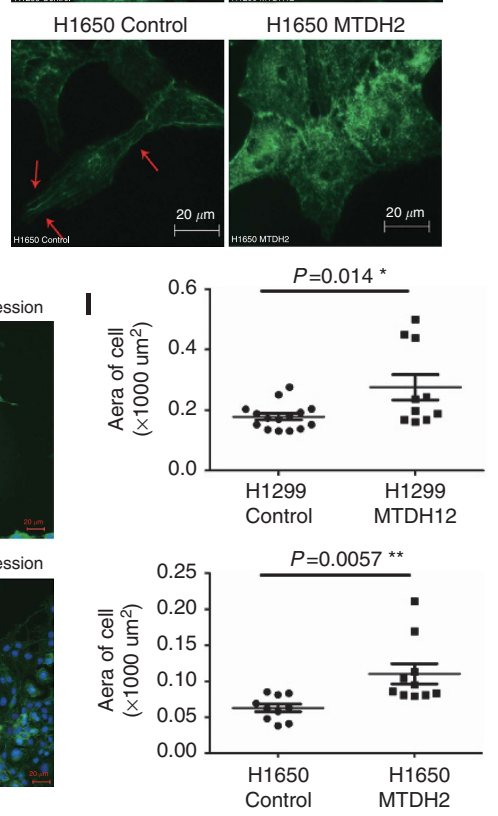
expression of MTDH have no significant difference in the two histological types of lung cancer. Figure 1C also shows high expression and low expression of MTDH protein in the two histological types.

MTDH inhibits cell proliferation in vitro. With evidence that MTDH was correlated with NSCLC, the effect of MTDH on carcinogenesis was then investigated in vitro. It is shown in ATCC website that H1299 was derived from metastatic lymph node and H1650 was from metastatic pleural effusion while A549 was from primary carcinoma. The mRNA level of MTDH was relatively higher in A549 cell and lower in H1299 and H1650 cells (Supplementary Figure S3), which was in accordance with the result in NSCLC patients.

H1299 and H1650 cell lines were then chosen to establish MTDH-overexpressing cells. After selection, H1299 MTDH5 (M5) and H1650 MTDH1 (M1) cells with mildly upregulated MTDH expression and H1299 MTDH12 (M12) and H1650 MTDH2 (M2) cells with highly upregulated $\mathrm{MTDH}$ expression were chosen according to the verification of both mRNA and protein level (Figure 2A).

MTT assay was used to assess the proliferative ability. Using absorbance at $24 \mathrm{~h}$ as reference, cell proliferation ratio was obtained by absorbance at 48,72 and $96 \mathrm{~h}$. The result suggested that compared with control cell proliferation rates in MTDH-overexpressing cells were decreased (Figure 2B).
The newly synthesised DNA was further evaluated by EdU-binding ability. After synchronisation, positive cells with EdU in MTDH-overexpressing cells were significantly reduced compared with control cells, as shown in Figure 2C.

Anchorage-independent growth ability, one hallmark of cell neoplastic transformation, was tested by soft agar assay. The result revealed that both the number and size of colonies in agar were significantly reduced in MTDH-overexpressing cells (Figure 2D).

We then examined the effect of MTDH expression on cell cycle to explore the mechanism. The percentage of $\mathrm{S}$ phase in cell cycle were $69.87 \%$ in $\mathrm{H} 1650$ control cells, $41.32 \%$ in H1650 M1 cells and $28.9 \%$ in H1650 M2 cells $(P<0.001$; Figure $2 \mathrm{E})$. The result suggested that cell cycle was arrested and cell proliferation was inhibited when MTDH expression was increased.

MTDH inhibits cell migration and invasion in vitro. Scratch wound and transwell assays were applied to assess the motility and invasive properties. As shown in Figure 3A, migratory ranges in MTDH-overexpressing cells were reduced at 10 and $24 \mathrm{~h}$. At $10 \mathrm{~h}$, the scratch coverage was decreased in H1299 M5 and M12 cells $(P<0.001$; Figure $3 \mathrm{~A})$. The coverage at $24 \mathrm{~h}$ was also significantly reduced $(P<0.001$, Figure $3 \mathrm{~A})$.

The results of transwell assay displayed that after $12 \mathrm{~h}$ migratory cells through the chamber were decreased in H1299 MTDHoverexpressing cells (Figures $3 \mathrm{~B}$ and $\mathrm{C}$ ). The similar result was obtained in H1650 cells (Figures 3B and C). Compared with control cells, the number of invasive cells through matrigel in
A
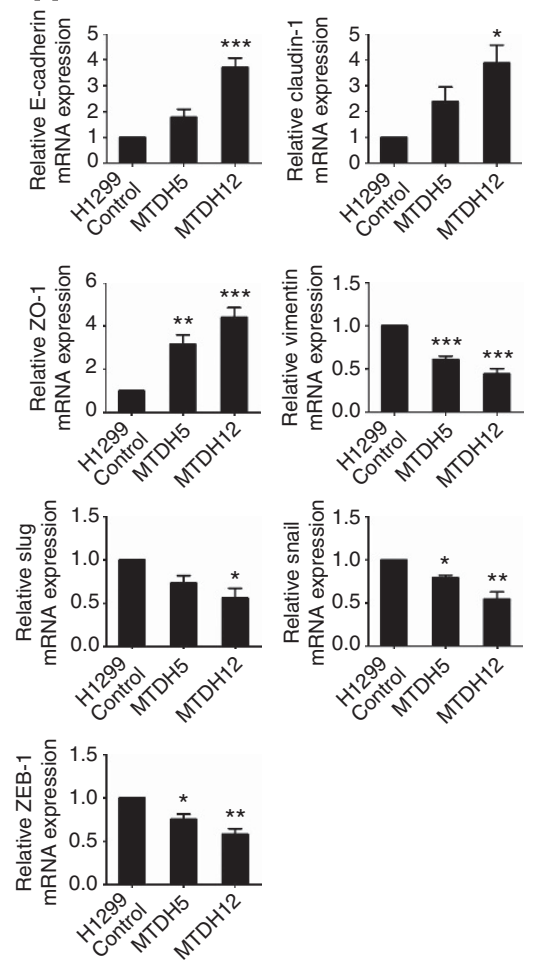

B

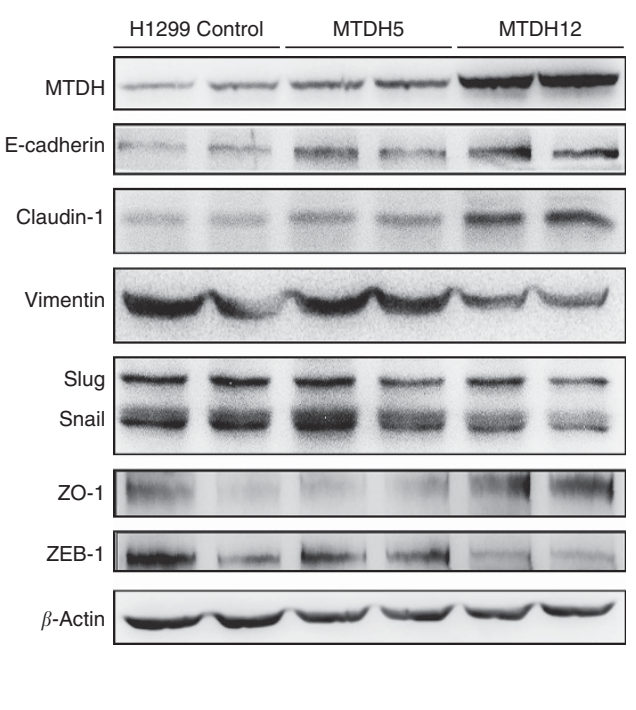

C

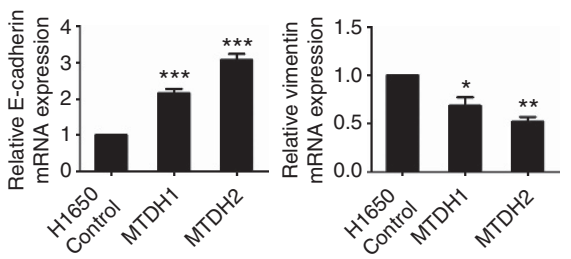

D

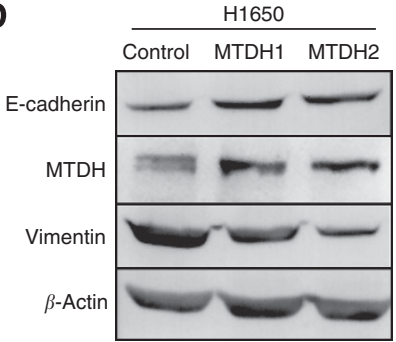

Figure 4. Suppression of epithelial-mesenchymal transition in cells by MTDH overexpression. (A) Q-PCR analysis of EMT markers mRNA expression in H1299 cells. The mRNA expression levels of E-cadherin, Claudin-1 and ZO-1 were significantly increased and those of Vimentin, Slug, Snail and ZEB-1 were decreased in MTDH-overexpressing H1299 cells. Data are mean \pm s.d. ${ }^{\star} P<0.05,{ }^{\star \star} P<0.01,{ }^{\star \star \star} P<0.001$ compared with control. (B) Western blotting analysis of EMT markers' protein expression in $\mathrm{H} 1299$ cells. The protein levels of E-cadherin, Claudin-1, ZO-1 were increased and those of Vimentin, Slug, Snail and ZEB-1 were accordingly decreased in MTDH-overexpressing H1299 cells. (C) Q-PCR analysis of EMT markers' mRNA expression in $\mathrm{H} 1650$ cells. The mRNA expression of E-cadherin was significantly increased and that of Vimentin was decreased in MTDH-overexpressing $\mathrm{H} 1650$ cells. Data are mean \pm s.d. ${ }^{\star} P<0.05,{ }^{\star \star} P<0.01,{ }^{\star \star \star} P<0.001$ compared with control. (D) Western blotting analysis of EMT markers' protein expression in $\mathrm{H} 1650$ cells. The protein expression of E-cadherin was increased and that of Vimentin was accordingly decreased in MTDH-overexpressing H1650 cells. 
MTDH-overexpressing cells was also significantly reduced after $24 \mathrm{~h}$ (Figure $3 \mathrm{~B}$ and $\mathrm{C}$ ).

MTDH regulates actin cytoskeletal remodelling. Under light microscope, the control cell exhibited an elongated, spindle-shaped and mesenchymal-like morphology, while MTDH-overexpressing cells presented an epithelial-like polygon appearance, smoother cell edge and increased cell adhesion (Figure 3D). IF showed that MTDH dominantly existed in cytoplasm. When MTDH level was overexpressed, F-actin-enriched filopodia extensions were decreased, cell size was increased and lost mesenchymal feature (Figure 3E). In Figure 3F, F-actin filament aggregation and filopodia in the leading edge was observed in control cell and was significantly decreased in MTDH-overexpressing cells.

Early cell migration observed at $6 \mathrm{~h}$ after scratch demonstrated that there were distorted and elongated cells moving to scratched area in control cells (Figure 3G). At migration front, actin cytoskeleton was remodelled to pro-metastatic, spindle-shaped and mesenchymal-like structure in H1650 control cell. Actin-rich filopodia was shown in the leading edge of H1299 control migratory cells (Figure $3 \mathrm{H}$ ). The area of migratory cell at the leading edge was measured, and results showed that cell size was significantly increased in MTDH-overexpressing cells (Figure 3I).

MTDH inhibits EMT in vitro. To further confirm the effect of MTDH expression on metastasis, we investigated the changes of EMT markers. The mRNA expression levels of epithelial markers E-cadherin, Claudin-1 and ZO-1 was significantly increased in H1299 M12 cells (Figure 4A). On the contrary, the mRNA expression levels of mesenchymal marker Vimentin and EMTinduced factors Slug, Snail and ZEB-1 were inhibited (Figure 4A).

Results of western blotting also revealed that the protein expression levels of epithelial markers E-cadherin, Claudin-1 and ZO-1 were increased while the expression of MTDH was increased, whereas the marker proteins of mesenchymal Vimentin, Slug, Snail and ZEB-1 were decreased (Figure 4B).

The similar results were also observed in H1650 cells, as E-cadherin expression was increased and Vimentin expression was decreased in both mRNA and protein levels when the MTDH expression in H1650 cells was overexpressed (Figure 4C and D).

The classical tumour-promoting AKT signal pathway was also detected in our study but was not activated when MTDH expression was altered (Supplementary Figure S5).
A

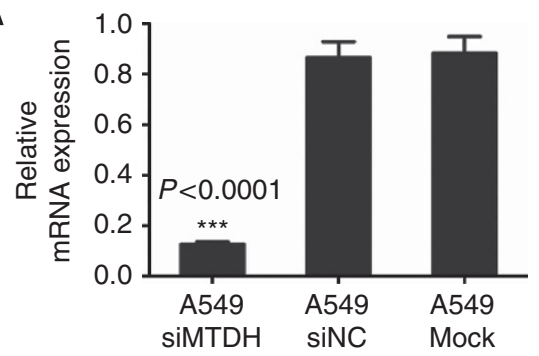

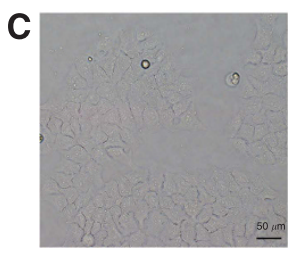

siNC

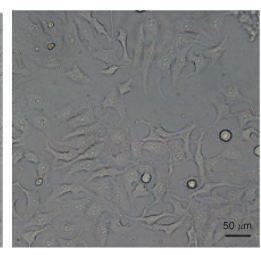

siMTDH

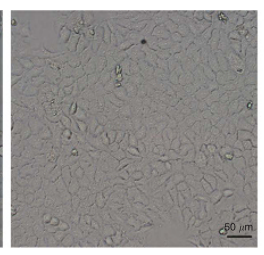

TGF $\beta-$

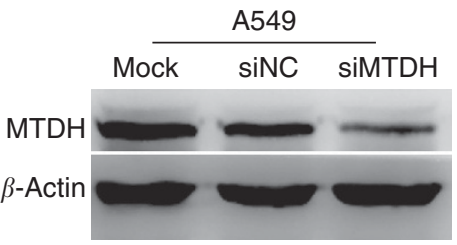

D

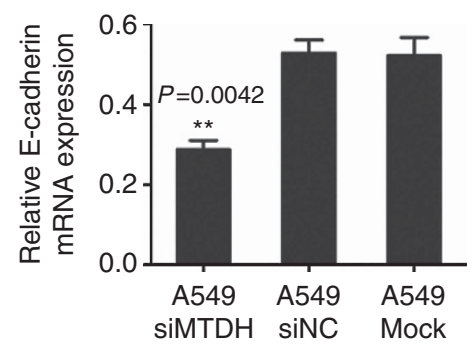

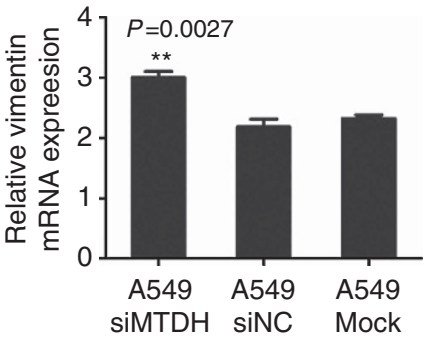

B

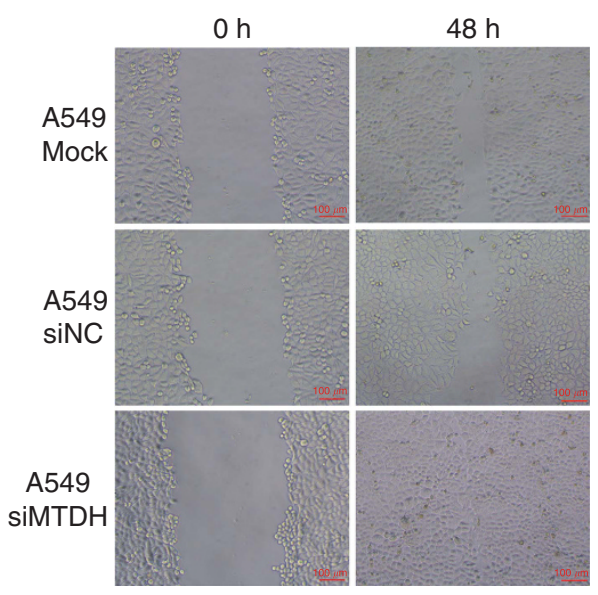

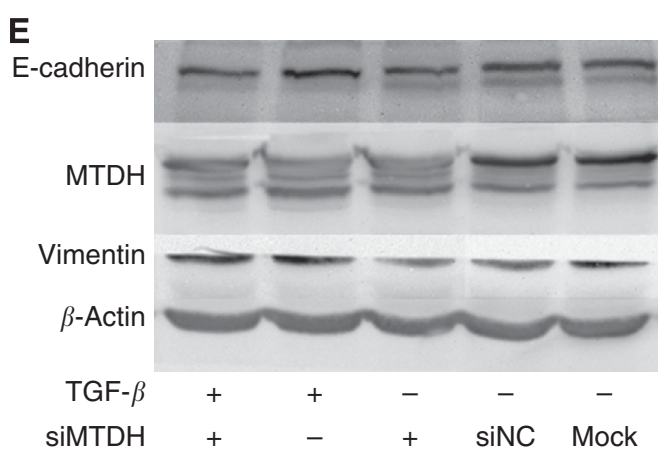

Figure 5. Knockdown of MTDH expression increases migration in A549 cells. (A) Q-PCR and western blotting analyses for expression of MTDH in selected knockdown A549 cells (A549 siMTDH) by transfecting MTDH-targeting siRNA. Negative control siRNA-transfected A549 cells (A549 siNC) and only lipo-transfected A549 cells (A549 Mock) served as negative control. GAPDH and $\beta$-actin were, respectively, used as control for mRNA and protein. ${ }^{\star \star \star} P<0.0001$ compared with control. (B) Migration ability of A549 cells. Migration ability of A549 siMTDH was significantly decreased than that in A549 siNC and A549 Mock. (C) Cell morphology of A549 cells. Typical polygonal epithelial structure in A549 siNC was transformed into slender, reduced cell adhesive, spindle-shaped mesenchymal-like structure in A549 siMTDH cells, which was similar to the cell morphology after TGF- $\beta$ stimulation. (D) Q-PCR analysis of EMT markers' mRNA expression in A549 cells. The mRNA expression of E-cadherin was significantly decreased and that of Vimentin increased in A549 siMTDH cells. Data are mean \pm s.d. ${ }^{\star} P<0.05,{ }^{\star \star} P<0.01$ compared with control. (E) Western blotting analysis of EMT markers' protein expression in A549 cells. E-cadherin expression was decreased and Vimentin expression was increased in A549 siMTDH cells and was also similar to the changes after TGF- $\beta$ stimulation. The downtrend of E-cadherin expression and uptrend of Vimentin expression was increased after TGF- $\beta$ stimulation in A549 siMTDH cells. 
Knockdown of MTDH expression increases migration in A549 cells. To ascertain whether decreased MTDH expression could increase NSCLC cell metastasis, we chose another NSCLC cell line A549 which has relatively higher MTDH expression (Supplementary Figure S3). The endogenous MTDH expression in A549 cells was knocked down by siRNA (Figure 5A). As a result, the migration ability was decreased in A549 siMTDH cells (Figure 5B).

The observation of cell morphology suggested that in A549 siMTDH cells typical polygonal epithelial cell structure was transformed into slender, reduced cell adhesive, mesenchymal-like spindle-shape, which was similar with the cell morphology after TGF- $\beta$ stimulation (Figure 5 C).

The decreased E-cadherin and increased Vimentin in A549 siMTDH cells were observed by western blotting, which was similar to the changes after TGF- $\beta$ stimulation as well (Figure $5 \mathrm{D}$ and $\mathrm{E}$ ). Interestingly, the changes of E-cadherin and Vimentin expression levels were increased after TGF- $\beta$ stimulation in A549 siMTDH cells (Figure 5E).

MTDH inhibits tumorigenesis and tumour growth in vivo. Tumorigenesis and tumour growth in subcutaneous tumour-implanted $\mathrm{BALB} / \mathrm{c}$-nu mice were observed 8 weeks after injection. Tumorigenesis was observed in a total of 12 mice in the H1299 control group, while only three mice had tumours in the H1299 M12 group (Figure 6A). According to the maximum and minimum diameters of the obtained tumour, the mean tumour size was $1.208 \mathrm{~cm}^{3}$ in the $\mathrm{H} 1299$ control group and $0.667 \mathrm{~cm}^{3}$ in the $\mathrm{H} 1299 \mathrm{M} 12$ group $(P=0.0083$; Figure $6 \mathrm{~B})$. The average weight of tumours in the H1299 control group was $0.465 \mathrm{~g}$, while that in the $\mathrm{H} 1299 \mathrm{M} 12$ group was $0.246 \mathrm{~g}$, $P=0.0456$ (Figure 6C).

MTDH inhibits cancer metastasis in vivo. There were no obvious nodules on the surface of lung in both the H1299 control group and M12 group 12 weeks after tail vein injection in BALB/c-nu mice (Supplementary Figure S4A). However, the metastatic superficial lymphadenopathy was significantly different in the M12 group when compared with the control group. Both size and number of metastatic superficial lymph nodes were decreased when MTDH expression was increased (Figure 6D and E). In the control group, there were five lymph nodes from the neck, armpits and groins, with an average size of $55.7 \mathrm{~mm}^{3}$, while only two lymph nodes from left groin were obtained in the M12 group, with the average size of $9.86 \mathrm{~mm}^{3}(P=0.0007$, Figure 6E).

In addition, bloody pleural effusion was observed in four mice from the H1299 control group, while in the M12 group only one mouse had bloody pleural effusion (Supplementary Figure S4B).

\section{A}

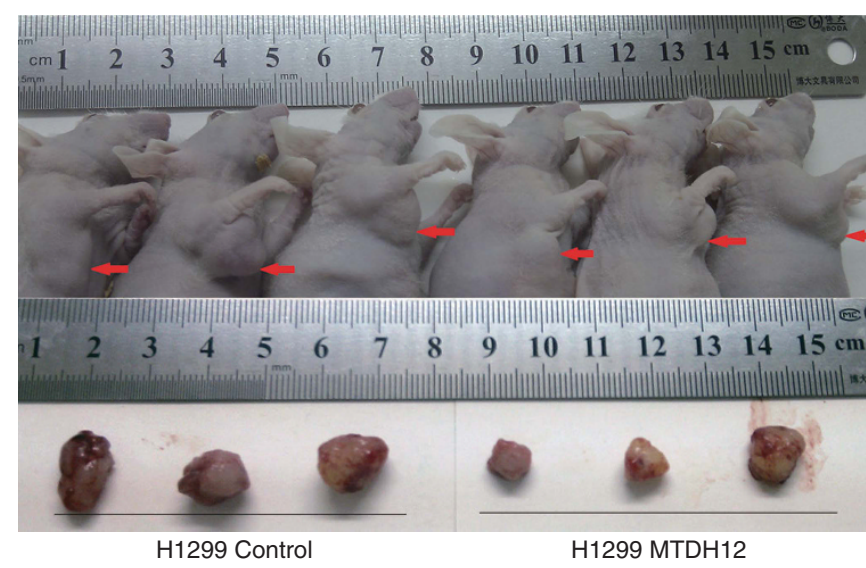

B

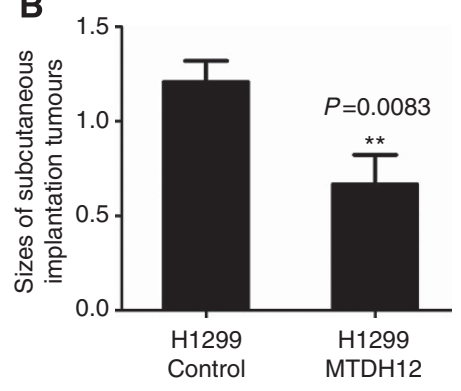

C

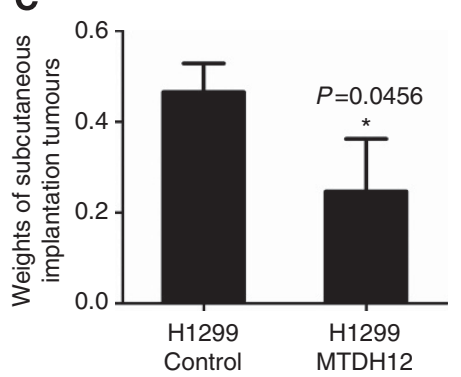

D

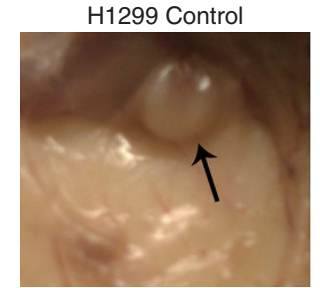

E

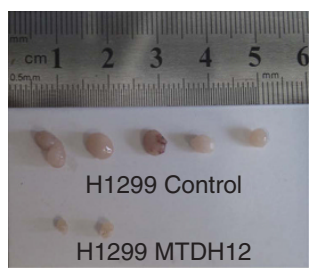

$\mathbf{F}$

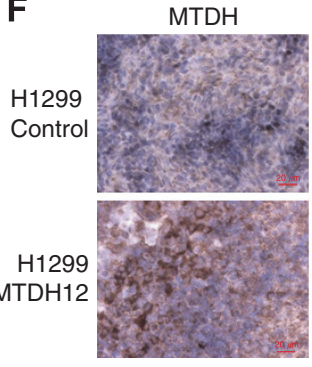

H1299 MTDH12
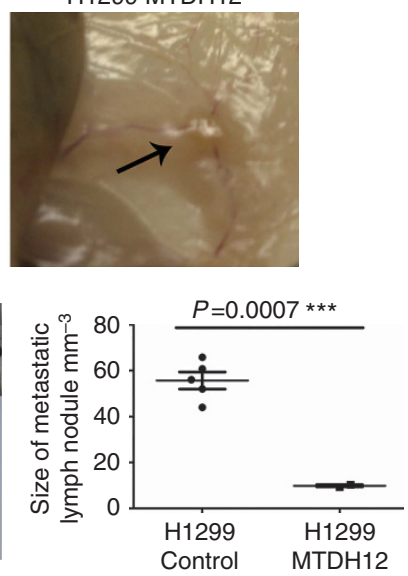

Vimentin
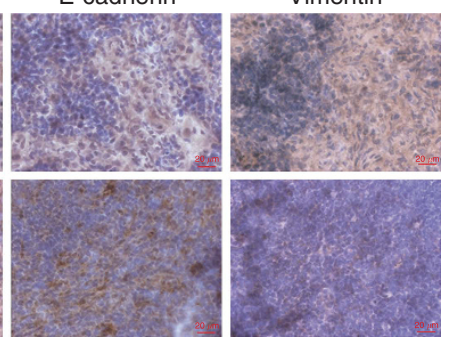

Figure 6. Suppression of tumorigenesis, tumour growth and metastasis by MTDH overexpression in vivo. (A) $2 \times 10^{6}$ cells were suspended in $100 \mu \mathrm{l}$ phosphate-buffered saline (PBS) and injected subcutaneously in BALB/c-nu mice (12 mice per group). At 8 weeks after injection, tumorigenesis and tumour growth were recorded. (B) Tumour sizes in the control and MTDH-overexpressing groups. The tumour size was calculated according to the maximum diameter and minimum diameter of the obtained tumour. The tumour sizes in MTDH-overexpressing group were significantly reduced. (C) Tumour weights in the control and MTDH-overexpressing groups. Tumour weights in the MTDH-overexpressing group were also inhibited by $\mathrm{MTDH}$ expression. Data are mean $\pm \mathrm{s}$.d. ${ }^{\star} P<0.05$, ${ }^{\star \star} P<0.01$ compared with control. (D) $1 \times 10^{6}$ cells were suspended in $100 \mu \mathrm{l}$ PBS and injected into the lateral tail vein of BALB/c-nu mice (5 mice per group). At 12 weeks after injection, all mice were killed, and the number of metastatic foci was determined. Arrowheads: enlarged superficial lymph node in the $\mathrm{H} 1299$ control cell and MTDHoverexpressing H1299 cell (H1299 MTDH12) groups. (E) Metastatic superficial lymphadenopathy. Both the size and number of metastatic superficial lymph node were significantly decreased in the H1299 MTDH12 group compared with the control group. Data are mean \pm s.d. ${ }^{\star \star \star} P=0.0007$ compared with control. (F) Immunohistochemical staining of metastatic superficial lymph node. The MTDH expression was confirmed to be increased in the H1299 MTDH12 group, and E-cadherin was increased and Vimentin was correspondingly decreased. 
Increased MTDH, increased E-cadherin expression and decreased Vimentin protein were seen in metastatic lymph nodes in the M12 group, detected by IHC (Figure 6F).

\section{DISCUSSION}

The present study for the first time demonstrates that MTDH expression was significantly correlated with lymph node metastasis, TNM stage and prognosis in NSCLC patients. Overexpression of MTDH can inhibit proliferation by cell cycle arresting, reduce the anchorage-independent growth in vitro and inhibit tumorigenesis and tumour growth in vivo. Moreover, overexpression of MTDH could significantly decrease cell migration and invasion ability. MTDH overexpression reverses pro-metastatic actin cytoskeleton remodelling and therefore inhibits EMT. By contrast, suppression of MTDH expression induced pro-metastatic actin cytoskeleton remodelling and EMT, which was similar to the TGF- $\beta$ stimulation. The decrease of number and size of metastatic lymph nodes in mice implanted with MTDH-overexpressing cells further confirmed the important role of $\mathrm{MTDH}$ in cancer metastasis, which was consistent with the result in cell lines.

MTDH protein was first identified as a novel protein that is designated as LYsine-Rich CEACAM1 co-isolated (LYRIC) protein, and CEACAM 1 is known to be a cell adhesion molecule and tumour suppressor (Thompson et al, 1994; Kleinerman et al, 1995; Britt et al, 2004). Britt et al (2004) demonstrated that MTDH co-localised with tight junction protein ZO-1 and occludins at in polarised epithelial cells. When junction complexes are disrupted, MTDH dissociates from ZO-1 and is recruited during the maturation of the tight junction complex (Britt et al, 2004).

Altered MTDH expression was reported in some cancers, including breast cancer, hepatocellular carcinoma, head and neck squamous cell carcinoma and prostate cancer, showing prognostic benefits (Kikuno et al, 2007; Hu et al, 2009a; Nohata et al, 2011; Zhu et al, 2011). Increased MTDH expression in breast cancer and hepatocellular carcinoma predicted worse prognosis in patients (Hu et al, 2009a; Zhu et al, 2011). Brown and Ruoslahti (2004) identified a lung-homing domain in MTDH protein that selectively targeted phage as well as cells to the lung, which led a high trend of second metastasis to lung. As a protein that mediates specific adhesion to lung vasculature, the effect of MTDH on lung cancer was first found in our present study that MTDH expression was decreased in NSCLC tissues and low MTDH expression was significantly correlated with worse OS, showing that MTDH was a prognostic factor in NSCLC patients.

The tight junction proteins have been revealed to be tumour suppressor in lung cancer previously. Tight junction protein Claudin1 is identified as a metastasis suppressor and correlates with clinical outcome in lung adenocarcinoma (Chao et al, 2009). Another tight junction protein occludin was not detected in any cases of squamous cell carcinoma, large cell carcinoma, small cell carcinoma or large cell neuroendocrine carcinoma (Tobioka et al, 2004). Tight junctions function to regulate the electrical and solute permeability of the paracellular space, segregate the apicolateral part of the cell membrane and regulate the polarity of epithelial cell, therefore they have an important role in cancer development and metastasis (Sawada et al, 2003; Martin-Belmonte and Perez-Moreno, 2012; Soini, 2012). $\mathrm{MTDH}$, as a protein recruited in the mature tight junction complex, may contribute to the maintenance of tight junction.

As previously mentioned, disruption of cell-cell adhesion and detachment of cancer cells from the niche are the primary process in cancer metastasis (Mehlen and Puisieux, 2006). Cell dissociation, motility and invasiveness are the important early steps in the process (Fidler, 2003). In our study, data demonstrated that $\mathrm{MTDH}$ overexpression transformed the morphology of NSCLC cells from metastatic slender, spindleshaped mesenchymal-like shape to polylateral epithelial-like structure. The motility and invasiveness were also inhibited in MTDH-overexpressing cells. Additionally, we found that MTDH overexpression could inhibit both anchorage-independent and dependent growth in NSCLC cells by arresting cell cycle. These data suggested that MTDH may inhibit the initial step of cancer progression and metastasis.

However, there are some conflicting reports that increased MTDH expression enhances tumour metastasis by inducing EMT in breast cancer and hepatocellular carcinoma (Li et al, 2011; Zhu et al, 2011). EMT, an initial event in cancer metastasis, is identified to have three characteristics: (1) morphological changes from epithelial cells with an apical-basal polarity to spindle-shaped mesenchymal cells with migratory protrusions; (2) changes of differentiation markers from epithelial to mesenchymal; and (3) the functional changes that can invade through ECM (Boyer and Thiery, 1993; Zuk and Hay, 1994; Yang and Weinberg, 2008). Interestingly, we found that the three major changes of EMT were inhibited in NSCLC cell lines when MTDH expression was increased. When the expression of MTDH silenced, the suppression effect of EMT was inhibited. As a result, the expression of Vimentin is increased and the expression of E-cadherin is decreased, which reveals that the process of EMT is promoted. The morphology of cells is changed into mesenchymal-like, and the migration of cells is promoted. As a well-known EMT inducer, TGF- $\beta$ promoted EMT in A549 cell lines, and the changes in cell morphology and proteins were comparable in A549 siMTDH cells. These data together prove that MTDH is associated with metastasis through EMT in NSCLC. Moreover, p-AKT, a classical tumourpromoting signal pathway, was revealed to be active when MTDH is overexpressed in breast cancer (Hu et al, 2009b) but has no change in NSCLC cell lines in the present study (Supplementary Figure S4). Thus, our results supported the conclusion that MTDH expression in NSCLC functions to suppress cancer metastasis.

Unlike other cancers, the expression of MTDH in lung cancer is decreased, making it necessary to find out the silencing mechanisms. In the process of tumorigenesis and development of cancer, many genes, especially the tumour-suppressor genes, are silenced. The most frequent silencing mechanism is epigenetic modification. Several types of epigenetic inheritance systems are accepted to have an important role in the process, such as DNA methylation and chromatin remodelling, RNA transcripts, microRNAs, as well as the new long non-coding RNAs. MicroRNAs are demonstrated to be involved in the initiation and development of EMT. In many cancers, microRNA 200 (miR-200) family members (miRNA-141, miR-200a, b and $c$ and miRNA-429) are proved to suppress EMT by targeting ZEB1 and ZEB2, which are the transcriptional activators of EMT (Tryndyak et al, 2010; Bojmar et al, 2013; Song et al, 2014). It is also proven in NSCLC that loss of miR-200 EMT functions in a feedback loop with ZEB1 and ZEB2 to regulate the EMT (Schliekelman et al, 2011; Pacurari et al, 2013). ZEB1 is also proved in our study to be involved in the MTDH silencing promoting EMT, which indicates that microRNA may be involved in the MTDHsilencing mechanisms. In the further work, the epigenetic modification will be focused on to find out the MTDH-silencing mechanism.

Taken together, increasing expression of MTDH could inhibit cell proliferation, tumour formation and metastasis, and MTDH is an important factor for predicting metastasis and prognosis. It provides a new tool for early diagnosis, a new target for effective metastatic treatment and a new theoretical basis in NSCLC.

\section{ACKNOWLEDGEMENTS}

This work was supported by the National Natural Science Foundation of China (81370172) and the Natural Science Fund 
of Jiangsu Province (SBL201320035) to YS. We thank Professor Xingxu Huang of Nanjing University Model Animal Research Center, China for technical assistance in the construction of vector.

\section{CONFLICT OF INTEREST}

The authors declare no conflict of interest.

\section{REFERENCES}

Acloque H, Adams MS, Fishwick K, Bronner-Fraser M, Nieto MA (2009) Epithelial-mesenchymal transitions: the importance of changing cell state in development and disease. J Clin Invest 119(6): 1438-1449.

Bojmar L, Karlsson E, Ellegard S, Olsson H, Bjornsson B, Hallbook O, Larsson M, Stal O, Sandstrom P (2013) The role of microRNA-200 in progression of human colorectal and breast cancer. PLoS One 8(12): e84815.

Boyer B, Thiery JP (1993) Epithelium-mesenchyme interconversion as example of epithelial plasticity. APMIS 101(4): 257-268.

Braga VM (2002) Cell-cell adhesion and signalling. Curr Opin Cell Biol 14(5): $546-556$.

Britt DE, Yang DF, Yang DQ, Flanagan D, Callanan H, Lim YP, Lin SH, Hixson DC (2004) Identification of a novel protein, LYRIC, localized to tight junctions of polarized epithelial cells. Exp Cell Res 300(1): 134-148.

Brown DM, Ruoslahti E (2004) Metadherin, a cell surface protein in breast tumors that mediates lung metastasis. Cancer Cell 5(4): 365-374.

Chaffer CL, Weinberg RA (2011) A perspective on cancer cell metastasis. Science 331(6024): 1559-1564.

Chao YC, Pan SH, Yang SC, Yu SL, Che TF, Lin CW, Tsai MS, Chang GC, Wu CH, Wu YY, Lee YC, Hong TM, Yang PC (2009) Claudin-1 is a metastasis suppressor and correlates with clinical outcome in lung adenocarcinoma. Am J Res Crit Care Med 179(2): 123-133.

Fidler IJ (2003) The pathogenesis of cancer metastasis: the 'seed and soil' hypothesis revisited. Nat Rev Cancer 3(6): 453-458.

Gibbons DL, Lin W, Creighton CJ, Rizvi ZH, Gregory PA, Goodall GJ, Thilaganathan N, Du L, Zhang Y, Pertsemlidis A, Kurie JM (2009) Contextual extracellular cues promote tumor cell EMT and metastasis by regulating miR-200 family expression. Genes Dev 23(18): 2140-2151.

Gonzalez de Castro D, Clarke PA, Al-Lazikani B, Workman P (2013) Personalized cancer medicine: molecular diagnostics, predictive biomarkers, and drug resistance. Clin Pharmacol Ther 93(3): 252-259.

Gu JM, Lim SO, Park YM, Jung G (2008) A novel splice variant of occludin deleted in exon 9 and its role in cell apoptosis and invasion. FEBS $J$ 275(12): 3145-3156.

Hoover KB, Liao SY, Bryant PJ (1998) Loss of the tight junction MAGUK ZO-1 in breast cancer: relationship to glandular differentiation and loss of heterozygosity. Am J Pathol 153(6): 1767-1773.

Hu G, Chong RA, Yang Q, Wei Y, Blanco MA, Li F, Reiss M, Au JL, Haffty BG, Kang Y (2009a) MTDH activation by 8 q22 genomic gain promotes chemoresistance and metastasis of poor-prognosis breast cancer. Cancer Cell 15(1): 9-20.

Hu G, Wei Y, Kang Y (2009b) The multifaceted role of MTDH/AEG-1 in cancer progression. Clin Cancer Res 15(18): 5615-5620.

Kikuno N, Shiina H, Urakami S, Kawamoto K, Hirata H, Tanaka Y, Place RF, Pookot D, Majid S, Igawa M, Dahiya R (2007) Knockdown of astrocyteelevated gene-1 inhibits prostate cancer progression through upregulation of FOXO3a activity. Oncogene 26(55): 7647-7655.

Kleinerman DI, Troncoso P, Lin SH, Pisters LL, Sherwood ER, Brooks T, von Eschenbach AC, Hsieh JT (1995) Consistent expression of an epithelial cell adhesion molecule (C-CAM) during human prostate development and loss of expression in prostate cancer: implication as a tumor suppressor. Cancer Res 55(6): 1215-1220.

Li X, Kong X, Huo Q, Guo H, Yan S, Yuan C, Moran MS, Shao C, Yang Q (2011) Metadherin enhances the invasiveness of breast cancer cells by inducing epithelial to mesenchymal transition. Cancer Sci 102(6): 1151-1157.

Martin-Belmonte F, Perez-Moreno M (2012) Epithelial cell polarity, stem cells and cancer. Nat Rev Cancer 12(1): 23-38.
Martin TA, Jiang WG (2009) Loss of tight junction barrier function and its role in cancer metastasis. Biochim Biophys Acta 1788(4): 872-891.

Mehlen P, Puisieux A (2006) Metastasis: a question of life or death. Nat Rev Cancer 6(6): 449-458.

Nohata N, Hanazawa T, Kikkawa N, Mutallip M, Sakurai D, Fujimura L, Kawakami K, Chiyomaru T, Yoshino H, Enokida H, Nakagawa M, Okamoto Y, Seki N (2011) Tumor suppressive microRNA-375 regulates oncogene AEG-1/MTDH in head and neck squamous cell carcinoma (HNSCC). J Hum Genet 56(8): 595-601.

Pacurari M, Addison JB, Bondalapati N, Wan YW, Luo D, Qian Y, Castranova V, Ivanov AV, Guo NL (2013) The microRNA-200 family targets multiple non-small cell lung cancer prognostic markers in H1299 cells and BEAS-2B cells. Int J Oncol 43(2): 548-560.

Sawada N, Murata M, Kikuchi K, Osanai M, Tobioka H, Kojima T, Chiba H (2003) Tight junctions and human diseases. Med Electron Microsc 36(3): 147-156.

Schliekelman MJ, Gibbons DL, Faca VM, Creighton CJ, Rizvi ZH, Zhang Q, Wong $\mathrm{CH}$, Wang $\mathrm{H}$, Ungewiss $\mathrm{C}$, Ahn $\mathrm{YH}$, Shin $\mathrm{DH}$, Kurie JM, Hanash SM (2011) Targets of the tumor suppressor miR-200 in regulation of the epithelial-mesenchymal transition in cancer. Cancer Res 71(24): $7670-7682$.

Siegel R, Naishadham D, Jemal A (2013) Cancer statistics, 2013. CA Cancer J Clin 63(1): 11-30.

Soini Y (2012) Tight junctions in lung cancer and lung metastasis: a review. Int J Clin Exp Pathol 5(2): 126-136.

Song F, Yang D, Liu B, Guo Y, Zheng H, Li L, Wang T, Yu J, Zhao Y, Niu R, Liang H, Winkler H, Zhang W, Hao X, Chen K (2014) Integrated microRNA network analyses identify a poor-prognosis subtype of gastric cancer characterized by the miR-200 family. Clin Cancer Res 20(4): 878-889.

Thiery JP, Acloque H, Huang RY, Nieto MA (2009) Epithelial-mesenchymal transitions in development and disease. Cell 139(5): 871-890.

Thompson EW, Newgreen DF, Tarin D (2005) Carcinoma invasion and metastasis: a role for epithelial-mesenchymal transition? Cancer Res 65(14): 5991-5995; discussion 5995.

Thompson NL, Lin SH, Panzica MA, Hixson DC (1994) Cell CAM 105 isoform RNA expression is differentially regulated during rat liver regeneration and carcinogenesis. Pathobiology 62(4): 209-220.

Tobioka H, Tokunaga Y, Isomura H, Kokai Y, Yamaguchi J, Sawada N (2004) Expression of occludin, a tight-junction-associated protein, in human lung carcinomas. Virchows Arch 445(5): 472-476.

Tryndyak VP, Beland FA, Pogribny IP (2010) E-cadherin transcriptional down-regulation by epigenetic and microRNA-200 family alterations is related to mesenchymal and drug-resistant phenotypes in human breast cancer cells. Int J Cancer 126(11): 2575-2583.

Yang J, Weinberg RA (2008) Epithelial-mesenchymal transition: at the crossroads of development and tumor metastasis. Dev Cell 14(6): 818-829.

Yao Y, Yuan D, Liu H, Gu X, Song Y (2013) Pretreatment neutrophil to lymphocyte ratio is associated with response to therapy and prognosis of advanced non-small cell lung cancer patients treated with first-line platinum-based chemotherapy. Cancer Immunol Immunother 62(3): 471-479.

Yilmaz M, Christofori G (2009) EMT, the cytoskeleton, and cancer cell invasion. Cancer Metastasis Rev 28(1-2): 15-33.

Zhu K, Dai Z, Pan Q, Wang Z, Yang GH, Yu L, Ding ZB, Shi GM, Ke AW, Yang XR, Tao ZH, Zhao YM, Qin Y, Zeng HY, Tang ZY, Fan J, Zhou J (2011) Metadherin promotes hepatocellular carcinoma metastasis through induction of epithelial-mesenchymal transition. Clin Cancer Res 17(23): 7294-7302.

Zuk A, Hay ED (1994) Expression of beta 1 integrins changes during transformation of avian lens epithelium to mesenchyme in collagen gels. Dev Dynam 201(4): 378-393.

This work is published under the standard license to publish agreement. After 12 months the work will become freely available and the license terms will switch to a Creative Commons AttributionNonCommercial-Share Alike 3.0 Unported License.

Supplementary Information accompanies this paper on British Journal of Cancer website (http://www.nature.com/bjc) 